УДК 1 (91)

DOI 10.25205/2541-7517-2018-16-4-322-328

\author{
П. А. Бутаков \\ Институт философии и права СО РАН \\ ул. Николаева, 8, Новосибирск, 630090, Россия \\ pavelbutakov@academ.org

\section{ДИАЛОГ С ТЕОЛОГАМИ В СОВРЕМЕННОМ ИСТОРИЧЕСКОМ ФИЛОСОФСКОМ КОНТЕКСТЕ}

\begin{abstract}
Приведен краткий обзор нескольких конференций по аналитической теологии и аналитической философии религии, прошедших в текущем году. Обсуждаются способы конструктивного участия философов в теологических дискуссиях и возможные перспективы сотрудничества аналитических философов с теологами.

Ключевые слова: аналитическая теология, аналитическая философия, аналитическая философия религии.
\end{abstract}

В последние десятилетия аналитическая философия достигла того уровня развития, когда она может не только успешно осваивать новые области, но и вступать в конструктивный диалог с другими, нефилософскими дисциплинами. Поначалу, в первой половине XX в., сфера деятельности аналитических философов была весьма узкой в нее входили логика, философия науки и философия языка. Ранние аналитики исповедовали идеалы сциентизма и логицизма и чурались всего, что связано с религией и любой метафизикой [Лакс, 2015]. Сегодня ситуация в аналитическом лагере заметно изменилась - несмотря на то, что методологические приоритеты отцов-основателей продолжают служить отличительным признаком «аналитичности», их мировоззренческие идеалы уже давно перестали быть хоть сколько-нибудь нормативными. Метафизика и философия религии прочно вошли в список основных разделов аналитической философии, наряду с этикой, эстетикой и политической философией. В результате такой трансформации аналитические философы смогли выработать универсальный набор методик, позволяющих подвергать анализу 
любые системы знания и включаться в дискуссии даже за пределами своих традиционных дисциплин. Одной из таких междисциплинарных инициатив стал стартовавший десять лет назад проект «Аналитическая теология» [Crisp, Rea, 2009], в рамках которого профессиональные теологи при помощи инструментария аналитической философии пытаются находить новые решения традиционных богословских проблем.

Несмотря на то, что аналитическая теология была задумана как теологический проект, в его рамках регулярно происходят разнообразные совместные мероприятия и дискуссии между теологами и философами. В этом году мне удалось принять участие в работе нескольких таких междисциплинарных конференций, о которых я и намерен рассказать в данной статье.

Первыми в моем списке стали летняя школа и конференция «Природа Бога: личностные и неличностные концепции божества», прошедшие на базе теологического факультета университета Инсбрука (Австрия, 26.07-08.08.2018). Основной целью конференции был поиск возможных точек соприкосновения между классическим теизмом, доминирующим в традиционной теологии, и мировоззренческим натурализмом, который господствует в естественных науках. В качестве возможных промежуточных позиций между натурализмом и классическим теизмом были предложены к обсуждению концепции неличностного божества, пантеизма и панентеизма. Лейтмотивом большинства дискуссий было оправданное опасение, что неличностная концепция божества окажется неприемлемой для традиционного теистического мировоззрения. Как ни странно, вопрос о приемлемости данной концепции для натуралистического мировоззрения даже не обсуждался. Следует заметить, что большинство участников этой теологической конференции составляли не теологи, а аналитические философы - как атеисты, так и представители всех основных монотеистических религий: ислама, иудаизма и главных направлений христианства. Именно философы, а не теологи, определяли повестку дня и круг проблемных вопросов. Основные дискуссии были сосредоточены вокруг вопросов о том, каковы преимущества неличностной концепции божества, какие из традиционных божественных атрибутов применимы к неличностному божеству и какие метафизические, эпистемические и этические требования влечет за собой неличностная концепция. С моей точки зрения, наиболее интересными и содержательными были доклад Юджина Нагасавы (Бирмингем) об аксиологических проблемах пантеизма и доклад Джонатана Кванвига 
(Сент-Луис) о необходимости метатеологического подхода к теологическим теориям.

Следующая конференция по аналитической теологии, на которой мне удалось выступить в этом году, прошла в Католическом университете Лувена (Лувен-ля-Нёв, Бельгия, 12-14.09.2018). Она называлась «Аналитическая теология и Троица: тринитарное возрождение в аналитической традиции» и проходила на базе Междисциплинарного научно-исследовательского института религии, духовности, культуры и общества при Университете. Дело в том, что за последние двадцать лет одним из самых плодотворных направлений применения логического инструментария аналитической философии в теологии стала христианская доктрина Троицы. Аналитические философы предложили несколько новых метафизических моделей и подходов к интерпретации основополагающего христианского догмата о триединстве Бога, наиболее популярными из которых стали концепция относительной идентичности и концепция материальной конституции. Цель данной конференции состояла в том, чтобы подвести итоги успехов и неудач применения аналитического подхода к тринитарной теологии и обсудить новые направления исследований. Особенно порадовало то, что в конференции смогли принять участие некоторые из первопроходцев данного направления - Ричард Суинберн (Оксфорд) и Питер ван Инваген (Нотр-Дам, США). По итогам конференции можно смело утверждать, что аналитическая философия имеет огромный потенциал и может многое предложить церковной догматике, в частности, внести свой существенный вклад в осмысление и, по возможности, преодоление проблемы filioque, которая уже больше тысячи лет является предметом раздора между Восточными и Западными христианскими церквами.

Другие три конференции, о которых пойдет речь дальше, не имели прямого отношения к проекту «Аналитическая теология», но были весьма созвучны ему по духу и содержанию. С 17 по 21 сентября в Германии (Берген, Нижняя Саксония) прошел очередной раунд переговоров между представителями Международного лютеранского совета и Папского совета по содействию христианскому единству. Уже почти пятьсот лет в Западной церкви существует раскол между римо-католиками и лютеранами. После Второго Ватиканского собора при Римской Курии был учрежден совет, целью которого было преодоление церковного разделения посредством диалога с другими ответвлениями христианства, в частности, с лютеранами. С лютеранской стороны в этих переговорах участвовали теологи из Германии, США, Канады и Бразилии. На текущем этапе данного диалога 
одной из центральных тем обсуждения стал вопрос о присутствии Голгофской жертвы Христа в таинстве Евхаристии, на который лютеране традиционно дают отрицательный ответ, а римо-католики положительный. В какой-то момент участники переговоров пришли к выводу, что для разрешения теологических разногласий им необходима помощь профессиональных философов, поскольку римо-католическое объяснение вышеупомянутого таинственного присутствия затрагивает вопросы о природе пространства и времени. Интересно то, что традиционная для германских теологов «континентальная» философская подготовка оказалась бессильной для достижения взаимопонимания с оппонентами в метафизических областях. В результате было принято решение привлечь к диалогу аналитических философов с обеих сторон. В своем докладе «Евхаристическое преодоление времени» [Butakov, 2017] мне, насколько я могу судить, удалось убедительно показать, что некоторые популярные римо-католические теории являются совершенно неприемлемыми либо с точки зрения метафизики, либо с точки зрения самого римо-католического богословия. Я надеюсь, что дальнейшее привлечение аналитических философов к этому диалогу позволит преодолеть пятьсот лет взаимного непонимания между лютеранами и римо-католиками, что может открыть пути для их примирения.

Последние две конференции, о которых я хочу рассказать, прошли в России - в Воронеже и Москве. Воронежская конференция, проходившая в этот раз в ВГМУ им. Н. Н. Бурденко 21-22.09.2018, уже третий год подряд собирает отечественных аналитических философов, интересующихся философией религии. Успех этой конференции, на мой взгляд, связан с тремя нестандартными стратегическими решениями ее организатора - воронежского философа Игоря Гаспарова. Во-первых, в качестве темы каждой конференции выступает не какой-то проблемный вопрос или область исследований, а творчество конкретного современного аналитического философа. Так, в этом году конференция называлась «Quam dilecta: Философские темы от Питера ван Инвагена», а две предыдущие были посвящены работам Алвина Плантинги и Дэвида Льюиса. Поскольку количество российских аналитических философов весьма незначительно, и области их специализации не всегда пересекаются, то такие «персональные» темы конференций позволяют каждому участнику найти в творчестве обсуждаемого философа что-то свое. Во-вторых, для конференции выбран нетипичный для российской науки формат: доклад, комментарий и обсуждение. Для основных докладов назначаются комментаторы, которые имеют возможность заранее 
ознакомиться с содержанием доклада и подготовить развернутый ответ. Этот формат требует качественной подготовки как со стороны основных докладчиков, так и со стороны комментаторов. В результате получается конструктивная полемика, а не приевшееся показное высказывание частных мнений, демонстрация эрудиции и обмен оценочными суждениями. Наконец, в-третьих, организаторы конференций решили не связываться со спонсорами, грантами и меценатами и провести конференцию без какой-либо финансовой поддержки. Каждый участник конференции вынужден самостоятельно решать все вопросы о транспорте, проживании и их оплате. Эта стратегия, с одной стороны, дает организаторам полную независимость от чиновников, а с другой - отсекает тех незаинтересованных участников, которые посещают конференции лишь ради отчетности. Казалось бы, в современных условиях вряд ли можно было бы рассчитывать на то, что для такой конференции найдется достаточное количество участников. Тем не менее число желающих ежегодно растет, причем приезжают и гости из-за рубежа, так что значительную часть докладов и обсуждений приходится делать на английском языке. Все это указывает на то, что аналитическая философия религии весьма востребована в нашей стране, и в недалеком будущем она сможет стать площадкой для конструктивного обсуждения теологических и межцерковных вопросов современности.

Последнее мероприятие в моем списке прошло на базе сектора философии религии Института философии РАН (Москва, 25-26.09.2018) в рамках проекта «Теистические и атеистические убеждения и стандарты рациональности». Темой этой конференции стала «этика веры» - междисциплинарное направление в аналитической эпистемологии, этике и философии сознания. Доклады были посвящены обсуждению вопросов о том, каковы критерии рациональности наших убеждений, в чем состоят эпистемические, моральные и практические нормы для формирования убеждений или отказа от них, и какой должна быть корреляция между убеждениями и фактами. Несмотря на то, что сама по себе «этика веры» не имеет прямого отношения к философии религии, тем не менее, все эти вопросы напрямую касаются проблемы рациональности религиозных убеждений, что отразилось в большей части представленных на конференции докладов. Поиск универсальных критериев рациональности и нормативности для религиозных убеждений, помимо чисто теоретической ценности, может способствовать развитию диалога между последователями самых разных теистических и атеистических воззрений, преодолению замкнутости, ксенофобии и фундаментализма. 
Завершая этот краткий обзор, следует еще раз задаться вопросом о том, какую именно роль играют аналитические философы в теологических дискуссиях. Очевидно, что философы не могут и не должны пытаться самостоятельно решать теологические проблемы - эта задача целиком лежит на самих теологах. Более того, философам также не следует вступать в полемику с теологами в качестве их оппонентов по теологическим вопросам, ведь опять же защита и опровержение теологических убеждений не входят в профессиональную компетенцию философов. Мне представляется, что аналитическая философия со всем своим универсальным инструментарием может оказаться наиболее удачной площадкой для теологических дебатов. Философы могут (и, по-моему, должны) принимать участие в теологических спорах в качестве миротворцев и беспристрастных помощников, способных оценить и улучшить качество используемых доводов, отследить применение некорректной аргументации, а также предложить новые направления развития диалога. Напоследок хочется сослаться на образ философии как «разговора человечества», предложенный Ричардом Рорти. Согласно Рорти, именно сама возможность диалога является окончательным контекстом познания, и в этом разговоре человечества философы выступают не в качестве носителей некоего сокровенного знания или судей, чей голос всегда перевешивает все остальные. Роль философов - влезать в чужие разговоры со своими полезными комментариями (useful kibitzing), а их право вторгаться в чужие дискуссии обусловлено знакомством с универсальной аргументацией и знанием наизусть тех за и против, на которые другим участникам разговора еще предстоит не раз наткнуться [Рорти, 1997. C. 288, 291].

\section{Список литературы}

Лакс М. Дж. Метафизика в аналитической традиции // Философский журнал. 2015. Т. 8, № 2. С. 5-15.

Рорти Р. Философия и зеркало природы. Новосибирск, 1997.

Butakov P. The Eucharistic Conquest of Time // Faith and Philosophy. 2017. Vol. 34. No. 3. P. 247-271.

Crisp O. D., Rea M. C. Analytic Theology: New Essays in the Philosophy of Theology. Oxford: OUP, 2009. 


\author{
P. A. Butakov \\ Institute of Philosophy and Law SB RAS \\ 8 Nikolaev Str., Novosibirsk, 630090, Russian Federation \\ pavelbutakov@academ.org
}

\title{
A DIALOGUE WITH THEOLOGY IN THE CONTEMPORARY HISTORICAL PHILOSOPHICAL CONTEXT
}

The article provides a brief description of several conferences on analytic theology and analytic philosophy of religion, which took place earlier this year. It discusses ways of beneficial participation of philosophers in theological debates, and the promising perspectives of the collaboration of analytic philosophers and theologians.

Keywords: analytic theology, analytic philosophy, analytic philosophy of religion.

\section{References}

Butakov P. The Eucharistic Conquest of Time. Faith and Philosophy, 2017, vol. 34, no. 3, p. 247-271.

Crisp O. D., Rea M. C. Analytic Theology: New Essays in the Philosophy of Theology. Oxford, OUP, 2009.

Loux M. J. Metafizika v analiticheskoi traditsii [Metaphysics in Analytic Tradition]. Filosofskii zhurnal [Philosophy Journal], 2015, vol. 8, no. 2, p. 5-15. (In Russ.)

Rorty R. Filosofiya i zerkalo prirody [Philosophy and the Mirror of Nature]. Novosibirsk, 1997. (In Russ.) 